\title{
Antimicrobial activity of volatile constituents extracted by hydrodistillation and headspace solid-phase microextraction methods from different parts of Saudi Anethum graveolens L.
}

\author{
Hanan Aati ( $\square$ hati@ksu.edu.sa ) \\ King Saud University \\ Shagufta Perveen \\ King Saud University \\ Raha Orfali \\ King Saud University \\ Juergen Wanner \\ Kurt Kitzing Co. Hinterm Alten Schloss \\ Sultan Aati \\ University of Western Australia \\ Areej Al-Taweel \\ King Saud University \\ Oliver Kayser \\ TU Dortmund University
}

\section{Research Article}

Keywords: Anethum graveolens L., hydrodistillation, headspace solid-phase microextraction, chemical composition, antimicrobial potency

Posted Date: May 5th, 2021

DOI: https://doi.org/10.21203/rs.3.rs-408647/v1

License: (c) (i) This work is licensed under a Creative Commons Attribution 4.0 International License. Read Full License 


\section{Abstract}

Anethum graveolens $\mathrm{L}$. (AG) is one of the most important aromatic herb, used in folk medicine to cure many illinesses. The current work was carried to compare the chemical composition and the antimicrobial potency of Saudi AG essential oils obtained from different parts. The oils constituents were extracted by two techniques; the Headspace Solid-phase Microextraction (HS-SPME) and traditional hydrodistillation (HD), then the constituents of each extracted oil were quantitavly and qualitatively identified. The essential oil isolated from AG seeds exhibited the highest antimicrobial activity comparing to other essential oils isolated from other parts of the same plant followed by flowers, leaves and stems, respectively. Interestingly, all tested AG essential oil samples showed stronger antifungal activity against Aspergillus parasiticus than the control antifungal itraconzole used in the study. Our finding suggest that AG seed essential oil may be considered as an alternative safe remedy derived from a natural source used to cure many uncomplicated infections. Up to our knowledge, this is the first report on the chemical compostion of the Saudi AG oils isolated by different methods with a comparable testing against different pathogenic microorganisms.

\section{Introduction}

Anethum graveolens $\mathrm{L}$. is an important aromatic annual herb. It is a member of the Apiaceae family which is distributed in Southwest Asia, Mediterranean and native to South-East Europe. It is commonly known as dill in English and "Shabat [uा" in Arabic $^{1}$. It is cultivated since ancient times and found closely related to the species of Indian dill ( $A$. sowa) and European dill (A. graveolens). Mediterranean region countries in Eastern Europe, India and Russia are main producers of dill essential oil ${ }^{2}$.

The seeds of $A$. graveolens are used in folk medicine as appetizer, carminative, diuretic, stomachic, digestive, sedative and in hemorrhoids ${ }^{3,4}$. Chewing of the seeds improves bad smell of breath or halitosis. Anethum graveolens stimulates milk flow in lactating/nursing mothers, and is often given to livestock for this reason. It also cures mental disorders, urinary infections and piles $^{5}$. This plant is one of the additive used in gripe water usually given for relief of colic pain and hiccups in babies/infants and flatulence in young children ${ }^{6}$. Furthermore, it is used as a natural flavor enhancer in many food items, particular in sauces, salads, soups, sea foods, fried meats and mainly in pickles. The essential oil is extracted from leaves, seeds and stems, used as a flavoring agent in food and beverages due to its pleasant aroma. As well, the essential oil is used as perfume to aromatize soaps, detergents and cosmetics ${ }^{7}$.

The phytochemical screening of this plant showed that flowers, seeds, leaves and stems were rich in polyphenols, tannins, terpenes, cardiac and flavonoids glycosides ${ }^{4,6}$. Various pharmacological activity has been reported from AG plant parts such as; anti-hypercholesterolemic, chemo-preventive effects, antimicrobial, antioxidant, antihyperlipidemic, anti-ulcer, mucosal protective, antisecretory, anticancer, antidiabetic, anti-inflammatory, insecticidal and analgesic activities ${ }^{5}$.

Hydrodistillation (HD) is the most well-known extraction technique used to isolate the volatile constituents from the plant tissue, but it is time consuming and needs large quantity of sample as well as, losses of low-boiling-point volatile constituents during solvent expulsion. Headspace solid-phase microextraction (HS-SPME) is an attractive alternative method for the extraction and enrichment of volatile constituents from various plant materials. It utilizes a fine quartz fiber with a polymeric coating to extract organic compounds from their matrix and directly transfer them into the injector of a gas chromatograph for thermal desorption and analysis. It is now considered a new extraction method. However, the extraction depends on the characteristics of the fibers used and the volatile constituents' characteristic. Thusly, the volatile profile may not precisely reflect the proportion of volatile components from the medicinal plant by HS-SPME sampling ${ }^{8}$.

The essential oils of the seeds, flowers, leaves and stems of AG plant were separately extracted by using HS-SPME and HD extraction method. Then, the GC/MS analyzed the volatile constituents. Fiber coatings divinylbenzene/carboxen on polydimethylsiloxane (DVB/CAR/PDMS) was used for SPME methods. The current study is the first report involving rapid analysis of volatile components of seeds, flowers, leaves and stems of AG essential oils growing in Jazan province, Saudi 
Arabia by HS-SPME and HD methods. As well as, the antimicrobial activity for obtained essential oils that isolated from different part of AG were compared and assessed against various bacteria and fungus strains.

\section{Results}

The volatile compounds in AG essential oil samples (seeds, flowers, leaves and stems) were extracted by HS-SPME, followed by desorption and analysis with GC-MS. The volatile compounds in AG oil samples were also extracted by using HD method. The extracted compounds are tabulated in Table 1. Figs. S1-4 (a\&b), showed the GC chromatograms of AG essential oils of seeds, flowers, leaves and stems extracted by HS-SPME and HD methods. The typical total ion chromatograms (TIC) of the seeds, flowers, leaves, and stems essential oils obtained by HS-SPME and HD were shown in Fig. 1 and indicated the differences in the volatiles composition between the two methods. The chemical analysis results obtained by HD and HSSPME methods from AG seeds, flowers, leaves and stems are presented in Table 1 (were present in amount more than $0.05 \%$ ) in which compounds are listed in order of their elution on the column HP-5 MS. Retention indices (RI) calculated by GC capillary columns and obtained from literature were also listed in the tables.

In the AG essential oil of seed, forty volatile compounds were identified by HS-SPME method (Table 1 \& Fig. S1 a): monoterpenes (65.1\%) and miscellaneous classes (33.8\%). The most abundant compounds were dill apiole (33.3\%), limonene (30.8\%), carvone (17.7\%), trans-dihydrocarvone (12.2\%) and cis-dihydrocarvone (3.0\%). The minor compounds were verbenene $(0.4 \%), p$-cymenene $(0.2 \%)$, dihydrocarveol $(0.2 \%)$, myristicine $(0.2 \%)$ and elemicin $(0.2 \%)$. The HS-SPME analysis of AG essential oil of seeds led to identifying five major and five minor volatile components accounting for about $98.2 \%$ of the total identified components. HD analysis of AG seeds oil led to identification of twenty-five components accounting for $99.6 \%$ of the total GC peak area. The main components from the seeds oil were carvone (30.8\%), limonene (25.4\%), dill apiole (20.9\%) and trans-dihydrocarvone (15.4\%). The minor compounds were a-phellandrene $(0.5 \%)$, dihydrocarveol isomer II $(0.5 \%), p$-cymenene $(0.2 \%)$, dihydrocarveol isomer I $(0.2 \%)$, carveol $(0.2 \%)$ and myristicine $(0.2 \%)$, Table $1 \&$ Fig. $S 1_{b}$. The dominant compounds in the $A G$ essential oil of the seeds in both extraction methods were dill apiole, limonene, carvone, trans-dihydrocarvone, whereas carvone, limonene and camphor were reported earlier as the major constituents isolated from AG essential oil seed by using column chromatography (CC) and identified by NMR and GC-MS analysis ${ }^{1}$.

Moreover, the headspace oil extract of the flowers was rich in regard to oxygenated monoterpenes and monoterpene hydrocarbons ( $24.2 \%$ and $12.3 \%$, respectively), whereas the hydrodistilled oil extract contained mainly monoterpene hydrocarbons (59.7\%) and oxygenated monoterpenes (11.8\%). dill apiole (46.9\%), carvone (22.6\%), dill ether (8.5\%), cisdihydrocarvone (3.1\%), limonene (3.0\%), a-Phellandrene (2.9\%), trans-dihydrocarvone (1.4\%), myristicine (1.3\%), and sedanolide (1.2\%) were reported as the main compounds among the sixty constituents identified in the HS-SPME extract, representing $96.6 \%$ of the total components detected. The minor compounds in the AG essential oil flowers extract by using HS-SPME method were $p$-cymenene (0.6\%), camphor (0.5\%), neo-phytadiene (0.5\%) neo-iso-dihydrocarveol (0.4\%), 2-nonanone $(0.3 \%)$, a- pinene $(0.2 \%)$, iso-dihydrocarveol $(0.2 \%),(E)$-anethol $(0.2 \%)$ and $(E)$-ethyl cinnamate $(0.2 \%)$ as shown in Table $1 \&$ Fig. $\mathrm{S}_{\mathrm{a}}$.

From the other hand, in the flowers of AG essential oil, thirty-seven components were identified, representing $99.1 \%$ by HD method. The major components in the hydrodistilled oil from the flowers were a-phellandrene (34.6\%), dill apiole (20.0\%), limonene (14.7\%), carvone (11.3\%), dill ether (5.7\%), $\beta$-phellandrene (4.2\%), p-cymenene (1.5\%), a- pinene (1.4\%), transdihydrocarvone (1.4\%) and myristicine (1.4\%) (Table 1 \& Fig. S2 ${ }_{\mathrm{b}}$ ). Both AG extraction methods for flowers oil revealed to the dominant compounds were dill apiole, carvone, dill ether, limonene, trans-dihydrocarvone and myristicine.

As indicated in Table 1 \& Fig. S3 ${ }_{a}$, sixty-six components representing $83.1 \%$ of the total content were identified in the AG essential oil leaves by HS-SPME method included $40.9 \%$ monoterpenes and $10.2 \%$ sesquiterpenes. Sixteen of them were found over $1.0 \%$ peak area, while rest of constituents were in concentrations less than $1.0 \%$ peak area, Fig. 1. The major constituents of the leaves of AG essential oil by using HS-SPME extraction method were as follows; dill apiole (16.0\%), carvone (14.1\%), dill ether (7.3\%), a-phellandrene (6.1\%), neo-phytadiene (6.1\%), limonene (4.9\%), camphor (3.7\%), cis-dihydrocarvone (2.7\%), $E$ - 
anethol (2.1\%), $\beta$-phellandrene (1.4\%), p-Cymene (1.2\%), E-ethyl cinnamate (1.2\%), dimethyltetrahydrobenzofuranone (1.0\%), linalool (1.0\%) and bornyl acetate (1.0\%). The minor compounds which were found in the range of $0.2-0.9 \%$ peak area by HSSPME method and represented about $10.4 \%$ were; $E$ - $\beta$-caryophyllene $(0.9 \%)$, myristicin $(0.9 \%)$, cis-davanone $(0.9 \%), 2$ nonanone $(0.8 \%)$, trans-dihydrocarvone $(0.7 \%)$, E-nerolidol $(0.7 \%)$, carvacrol $(0.6 \%)$, cis-sabinene hydrate $(0.5 \%)$, a-pinene $(0.4 \%)$, Z-ethyl cinnamate (0.4\%), myrcene (0.3\%), $\gamma$-terpinene $(0.3 \%), E$ - $\beta$-farnesene $(0.3 \%)$, germacrene $D(0.3 \%), \beta$-selinene $(0.3 \%)$, elemicin $(0.3 \%)$, a-thujene $(0.2 \%)$, a-terpinene $(0.2 \%)$, artemisia ketone $(0.2 \%)$, terpinolene $(0.2 \%)$, cumin aldehyde $(0.2 \%)$, fenchyl acetate $(0.2 \%)$, carvotanacetone $(0.2 \%)$, E-methyl cinnamate $(0.2 \%)$ and $\delta$-cadinene $(0.2 \%)$.

In contrast, hydrodistillation analysis of the leaves essential oil of AG led to the identification of thirty-nine components accounting for $97.5 \%$ of the total GC peak area, as indicated in Table $1 \&$ Fig. $S 3_{b}$. Monoterpene as major class of the oil were extracted by HD extraction method by $82.5 \%$ with constituents like $\alpha$-phellandrene (61.4\%), dill ether (9.2\%), $\beta$-phellandrene (8.0\%), limonene (4.7\%), p-cymene (2.9\%), a-Pinene (2.5\%), dill apiole (2.6\%) and $E$-anethol (2.3\%). minor constituents were in the range of $0.2-0.9 \%$ peak area with myrcene $(0.8 \%)$, a-thujene $(0.4 \%)$, carvone $(0.4 \%)$, germacrene $\mathrm{D}(0.3 \%)$, sabinene $(0.2 \%)$, $\beta$-pinene $(0.2 \%)$ and terpinolene $(0.2 \%)$.

Furthermore, forty-eight and thirty-three components were extracted from the stem of AG essential oils by HS-SPME and HD method, respectively (Table 1 \& Figs. S4 ${ }_{\mathrm{a}, \mathrm{b}}$ ). $a$-Phellandrene, limonene, dill ether and dill apiole were the major compounds of stem oils; their percentages were $1.1 \%, 6.3 \%, 4.1 \%$ and $31.9 \%$ in HS-SPME and $58.9 \%, 4.5 \%, 10.3 \%$ and $1.5 \%$ in HD, respectively (Fig. 1). Whereas, myristicine (0.9\%), carvacrol (0.7\%), sedanolide (0.7\%), p-cymene (0.6\%), camphor (0.6\%), neo-isodihydrocarveol $(0.5 \%)$, 2-undecanone $(0.5 \%)$, ethyl palmitate $(0.5 \%)$, artemisia ketone $(0.4 \%)$, E-nerolidol ( $0.4 \%), 5$-methyl-3heptanone $(0.3 \%)$, linalool $(0.3 \%)$, iso-dihydrocarveol $(0.3 \%)$ and $E-\beta$-caryophyllene $(0.3 \%)$, were the minor constituents found in the range of $0.3-0.9 \%$ peak area by HS-SPME method, while a-thujene $(0.4 \%)$ was the only compound which found in this range by HD extraction method. Structures of major constituents present in the essential oils of AG seeds, flower, leaves and stems are illustrated Fig. 2.

The essential oils of AG samples (seeds, flowers, leaves and stems) were tested for antimicrobial activity gram-positive like Staphylococcus aureus (CP011526.1), Bacillus licheniformis (KX785171.1), Listeria innocua (DSM 20649) and gram-negative like Enterobacter xiangfangensis (CP017183.1), Escherichia fergusonii (CU928158.2) and Pseudomonas aeruginosa (NR117678.1) bacterial strains. In addition to, three pathogenic fungi Candida albicans (MF942350), Candida parapsilosis (MF942354) and Aspergillus parasiticus (CBS 100926), as shown in Table 2, were included to the assays. The oil from seeds at $20 \mu \mathrm{L}$ exhibited highest antimicrobial activity. The best activity was observed against Staphylococcus aureus strain with a diameter of inhibition equal to $25.0 \pm 0.00,17.0 \pm 0.10$, and $15.0 \pm 1.10 \mathrm{~mm}$ for the essential oil isolated from seeds, flowers and leaves, respectively. This strain had a lower sensitivity to the essential oil isolated from stems $(11.0 \pm 0.6 \mathrm{~mm})$ comparing to the commercial antibiotic tetracycline. The halo of inhibition for Bacillus licheniformis $(22.0 \pm 1.60$ and $18.0 \pm 1.90 \mathrm{~mm})$ of essential oils from seeds and flowers, respectively are greater than those for the remaining samples. By contrast, in antifungal assay the inhibitory actions of all the tested samples against Aspergillus parasiticus were significantly higher than the action of the control antifungal drug itraconazole Table 2.

\section{Discussions}

The aerial parts of AG seeds, flowers, leaves and stems were subjected to hydrodistillation for $4 \mathrm{~h}$ using a modified Clevengertype apparatus, with yields of $1.42 \%, 1.56 \%, 0.93 \%$, and $0.83 \%(\mathrm{v} / \mathrm{w})$, respectively. All oils showed a pale yellow, light green, intense yellow and yellow coloration with a strong fragrance. Also, oils of AG were obtained by HS-SPME by using PDMS/DVB/Carboxen fiber. To our knowledge, this study is the first report involving rapid analysis of volatile components of seeds, flowers, leaves and stems of AG essential oils growing in Jazan province, Saudi Arabia by HS-SPME and HD methods.

Myrcene, a-phellandrene, $p$-cymene, limonene, dill ether, carvone and dill apiole were found to be the common components of the AG plant seeds, flowers, leaves and stems essential oils by both extraction methods. Dill ether is the most important constituent of AG essential oils, which found in sufficient quantities in all parts; $46.9,33.3,16.0,31.9 \%$ in flowers, seeds, 
leaves, and stems, respectively by HS-SPME method while 20.0, 20.9, 2.6, 1.5\% in flowers, seeds, leaves, and stem, respectively by HD method. The second main volatile component of AG essential oils was a-phellandrene, which found in adequate quantities in flowers $(2.9 \%)$, seeds (traces), leaves $(6.1 \%)$ and stem $(1.1 \%)$ by HS-SPME method while in flowers $(34.6 \%)$, seeds (0.5\%), leaves (61.4\%) and stem (58.9\%) by HD method.

Comparing the composition of AG essential oils extracted by two different methods indicated that HS-SPME and HD, respectively, had the strng different numbers of extracted components. It seems that HS-SPME can isolate significantly more volatiles at small quantities in contrast to the HD method.

Although HD is the most popular, common, widespread and worthwhile conventional method for extracting essential oils from plant parts, it has some frailty. This method is a long-standing and laborious process and requires a substantial amount of plants sample. Furthermore, in the presence of water and lengthy heating time, it can be concluded that the essential oil has a higher percentage of sesquiterpenes. Although, monoterpenes might be susceptible to a chemical process, and several highly volatile compounds, such as a/ $\beta$-pinene and a-thujene evaporate during removal of the water/solvent by distillation. On the contrary, HS-SPME is a straightforward, expeditious method, environment friendless since it was solvent free, fast as well was better for more thermally sensitive volatile compounds and free from wastage of water. This method can be used for the qualitative analysis of volatile fractions from various plant samples simultaneously, requiring fewer samples. SPME is a method for the analysis of compounds, whereas HD can be used both for analysis and commercial production of essential oils. HD is a quantitative method for the extraction of volatiles from plant material, whereas SPME is not a quantitative technique. SPME is good if you want to get an overview of the composition of volatiles in a sample. It can be regarded as a semi-quantitative method at the most.

The oils or some of their constituents are very effective against many organisms, including bacteria and fungi. As typical lipophiles, they disrupt the structure of the cytoplasmic membrane and permeabilize them. In bacteria, the membranes' permeabilization is associated with loss of ions and reduction of membrane potential $\left.\right|^{9,10}$. For that, the present work was carried to compare and investigate the activity of $A G$ essential oils isolated from different parts against various strains of bacteria and fungi, the positive results will confirm the folkloric use of AG for curing many infectious diseases.

In vitro antimicrobial activity of the AG oil samples (seeds, flowers, leaves and stems) Table 2 possessed great antimicrobial activity against all tested microorganisms. Data analysis showed that the essential oil isolated from AG seeds exhibited the highest antimicrobial activity comparing to other essential oils isolated from other parts of the same plant following by flowers, leaves and stems, respectively. Previous findings showed that essential oils rich in carvone and limonene had stronger antimicrobial activity ${ }^{11,12}$. Our study carvone and its precursor limonene are the major components constituents in the AG essential oil seeds sample that probably originate its high antimicrobial property. The former sample's highest activity was observed against Staphylococcus aureus strain with a diameter of inhibition equal to $25.0 \pm 0.00 \mathrm{~mm}$ followed by Bacillus licheniformis with a diameter of inhibition $22.0 \pm 1.60 \mathrm{~mm}$ comparing to the commercial anti-biotics gentamicin and tetracycline. Interestingly, all tested AG essential oil samples showed stronger antifungal activity against Aspergillus parasiticus than the control antifungal itraconzole used in the study Table 2 . These results are consistent with data previously reported that essential oils extracted from dill plant have exhibited antifungal activity ${ }^{13,14,15}$. Up to our knowledge, this is the first report with a comparable testing of different parts of the Saudi AG essential oils (seeds, flowers, leaves and stems) against different pathogenic microorganisms.

\section{Materials And Method}

\subsection{Plant material}

The aerial part of wild A. graveolens at the flowering stage was collected from Jizan city of Saudi Arabia. In March 2019, carefully separated seeds, flowers, stems, and leaves then dried in the shade. It was identified by plant taxonomist Dr. Rajakrishnan Rajagopal, a botanist of the Science College Herbarium, King Saud University. A voucher specimen (\#24547) was 
deposited in the herbarium of the College of Science, KSU. All protocols involving plants adhered to relevant ethical guidelines/ regulations of King Saud University (Article \#14)

\subsection{Headspace- solid phase microextraction (HS-SPME) 4.2.1. Essential oils preparation for analysis}

Plant materials were placed in a $5 \mathrm{ml}$ headspace vial and enriched for $1 \mathrm{~h}$ on a SPME fiber (PDMS/DVB/Carboxen, SUPELCO part no. $57298-U$ ) at a temperature of $80^{\circ} \mathrm{C}$ in a metal block in such a way that the plant material was subjected to the elevated temperature while the SPME fiber was kept cold (room temperature). The enriched fiber was placed in the GC injector and the fiber desorbed for 1 minute at $250^{\circ} \mathrm{C}$.

\subsection{Hydrodistillation extraction (HD)}

\subsubsection{Essential oils extraction}

According to the standard procedure described in the literature (European Pharmacopeia, the freshly cut of AG seeds, flowers, leaves and stems $(300 \mathrm{~g}$ ) were subjected to HD by using Clevenger Apparatus for $4 \mathrm{~h}$, according to the standard procedure described in the literature, European Pharmacopoeia $(2005)^{16}$. The recovered oils were solubilized in petroleum ether and then filtered over anhydrous sodium sulfate to give a pale yellow, light green, intense yellow and yellow essential oils with a yield of $1.42,1.56,0.93$ and $0.83 \%(\mathrm{v} / \mathrm{W})$, respectively. Finally, the obtained oils were stored in amber glass vials under nitrogen at $4^{\circ} \mathrm{C}$ in the dark until further testing and analysis.

\subsubsection{Essential oils preparation for analysis}

Isolated EOs were diluted in dichloromethane (1:20) and $1 \mu \mathrm{L}$ of this solution was injected in the GC at a split ratio of 1:100.

\subsection{GC-FID and GC-MS analysis}

Gas chromatography-flame ionization detector (GC-FID) and GC-MS analyses were performed in one run using a MS-FIDsplitter consisting of a quartz Y-splitter, a short (ca. $20 \mathrm{~cm}$ ) $0.1 \mathrm{~mm}$ id fused silica restrictor column as an inlet to the GC-MS interface, and a ca. $1 \mathrm{~m} \cdot 0.25 \mathrm{~mm}$ deactivated fused silica column serving as a transfer line to the FID detector. The restrictor column was used to limit the MS vacuum flow and prevent the insertion of combustion gases from the FID, which operated at atmospheric pressure. Moreover, the analytical column flow had to be greater than the inflow to the MS detector, which was limited to about $1 \mathrm{~mL} / \mathrm{min}$ by the restriction line. The GC column flow should also be constant, otherwise the FID/MS split ratio would change with temperature. This configuration yielded an FID and MS chromatogram with almost identical retention times (RT), thus facilitating the FID peaks' assignment to each substance. We used a Thermo Fisher Scientific Trace GC Ultra with a split/split less injector heated at $250^{\circ} \mathrm{C}$ and connected to a $50 \mathrm{~m} \cdot 0.25 \mathrm{~mm} \cdot 1.0 \mu \mathrm{m} \mathrm{SE}-52$ ( $95 \%$ polydimethylsiloxane, $5 \%$ polydiphenylsiloxane) capillary column (prepared and tested for deactivation and separation efficiency in our lab, Kurt, $(1986)^{17}$, an FID detector operating at $250^{\circ} \mathrm{C}$, and a TriPlus RSH Autosampler.

For essential oils components identification, we used a Thermo Fisher Scientific ISQ mass spectrometer connected with a $\mathrm{GC} / \mathrm{MS}$ interface heating at $250^{\circ} \mathrm{C}$, an electron ionization mode at $70 \mathrm{Ev}$ and a filament with $50 \mu \mathrm{A}$. Furthermore, an ion source operating at $230^{\circ} \mathrm{C}$ and a scan range of $40-500 \mathrm{amu}$. The oven temperature use gradient program involved heating for $1 \mathrm{~min}$ at $60^{\circ} \mathrm{C}$, then heating increased to $230^{\circ} \mathrm{C}$ at a rate of $3^{\circ} \mathrm{C} / \mathrm{min}$, and a $230^{\circ} \mathrm{C}$ isotherm for $12.3 \mathrm{~min}$. The carrier gas was helium and flow at constant rate of $1.5 \mathrm{~mL} / \mathrm{min}$.

\subsection{Identification of the essential oils components}

The Thermo Xcalibur 2.2 software was used to identify the EO compounds by correlating the obtained mass spectra with the databases of the National Institute of Standards and Technology (The NIST 08) ${ }^{18}$, Wiley 8 th ed. (Wiley Registry $\left.{ }^{\mathrm{TM}}\right)^{19}$, Adams library ${ }^{20}$, Mass Finder terpenoids library ${ }^{21}$, and our own library. However, the mass spectra's simple comparison is not sufficient for a clear identification, especially for sesquiterpenes. Thus, the chromatogram position was also considered a second 
criterion determined by comparing the calculated retention indices $(\mathrm{RI})$ of the peaks with the corresponding literature data ${ }^{18,20,21}$ or reference compounds. The RI values were determined by measuring the RTs of a series of $n$-alkanes that were eluted across the entire chromatogram and were calculated according to the method of Van den Dool and Kratz ${ }^{22,23}$. Moreover, the EO components were quantified using normalized peak area calculations of the FID chromatogram without (by first approximation) relative FID-response factors.

\subsection{Antibacterial assay}

Agar diffusion methods were used in this study to assay the antibacterial activity of the essential oils against 9 different microbial strains including; Gram-positive; Staphylococcus aureus (CP011526.1), Bacillus licheniformis (KX785171.1) and Listeria innocua (DSM 20649) and the Gram-negative; Enterobacter xiangfangensis (CP017183.1), Escherichia fergusonii (CU928158.2) and Pseudomonas aeruginosa (NR-117678.1) bacterial strains. TSB tryptone soya broth media were used previously to grow the microorganisms as mentioned above for $24 \mathrm{~h}$. Nutrient agar plates were used to distribute $0.1 \mathrm{~mL}$ of the microbial suspensions. 10 and $20 \mu \mathrm{l}$ of each essential oil were spotted on the inoculated plates. Under sterile condition and after $15 \mathrm{~min}$, plates were then incubated at optimal growth condition culture of each strain. Free area without microbial growth was measured three times to detect the diameter of zone of inhibition and the mean were calculated. Gentamycin $10 \mu \mathrm{g}$ and Tetracycline $10 \mu \mathrm{g}$ were used as a positive control while ethanol used as a negative control.

\subsection{Antifungal activity}

All essential oils were tested for their antifungal activity, using well diffusion and broth microdilution method according to Gong and $\mathrm{Guo}^{24}$. The activity was tested against three pathogenic fungi; Candida albicans (MF942350), Candida parapsilosis (MF942354) and Aspergillus parasiticus (CBS 100926). $100 \mu \mathrm{l}$ of the sample solutions was smeared in SDA plate with approximately $3 \times 10^{6}$ colony-forming units (CFU) $\mathrm{mL}^{-1}$, following by incubation the plates at $37^{\circ} \mathrm{C}$ for 1 day. The zone of inhibition diameters (in $\mathrm{mm}$ ) were measured and the rates of growth inhibition were obtained according the following formula taking on consideration \pm SD as means:

\%Growth inhibition rate $=\left(d_{\mathrm{c}}-d_{\mathrm{s}}\right) /\left(d_{\mathrm{c}}-d_{0}\right) \times 100$

Where $d_{\mathrm{c}}$ : Diameter of the untreated control fungus, $d_{\mathrm{s}}$ : Diameter of the sample-treated fungus and $d_{0}$ : Diameter of the fungus cut

Each experiment was carried out in three independent replicates and the result is the average with standard deviation. Itraconazole was used as the positive control and ethanol was used as the negative control.

\subsection{Statistical analysis}

Data analysis was expressed as mean \pm standard deviation (SD) of three replicates. The data were subjected to one-way analysis of variance (ANOVA). Based on Microsoft Excel 2010 statistical package analyses, the significant differences were considered statistically significant values $p<0.05$.

\section{Conclusions}

This study described and analyzed the chemical profile of AG seeds, flowers, leaves and stems essential oils by using HSSPME and traditional HD extraction method. The results indicated that studies involving HS-SPME volatile oils are most effective and safe. Additionally, by using HS-SPME technique we can isolate many volatiles with small quantities which were not indicated by HD methods. Based on the current study, we recommend that the HS-SPME technique be suitable for the routine quality control analysis of medicinal plants at the analytical level. Finally, AG seeds oils' potent antimicrobial activity, perhaps attributed to the presence of carvone and its precursor limonene. Our data suggest that AG seed essential oil may be considered as an alternative method to cure uncomplicated superficial infections of staphylococcal etiology, such as folliculitis and impetigo. 


\section{Declarations}

\section{Author Contributions}

HYA and SP conceived and designed the experiments; HYA, SP, RO and JW performed the experiments; HYA, SP analyzed the data; HYA and SP wrote the primary draft of the manuscript; SY participated in the samples collections and manuscript writing and editing. All authors have read and agreed to the published version of the manuscript.

\section{Funding}

This research project was supported by a grant from the "Research Center of the Female Scientific and Medical Colleges", Deanship of Scientific Research, King Saud University.

\section{Additional Information}

Supplementary information accompanies this paper: are available in supplementary documents.

Competing Interests: The authors declare no competing financial interests.

\section{References}

1. Navneet, K., Khushminder, K. C., Amit, K., Ravinder, S. \& Urvashi, B. Antioxidant activity of Anethum graveolens L. essential oil constituents and their chemical analogues. J Food Biochem. 43, 127-182 (2019).

2. Henry, Y. S. et al. Hydrodistillation time affects dill seed essential oil yield, composition, and bioactivity. Industrial Crops and Products. 63, 190-196 (2015).

3. Jana, S. \& Shekhawat, G. S. Anethum graveolens: An Indian traditional medicinal herb and spice. Pharmacogn Rev. 4, 179-184 (2010).

4. Singh, G., Maurya, S., De Lampasona, M. P. \& Catalan, C. Chemical constituents, antimicrobial investigations, and antioxidative potentials of Anethum graveolens L. essential oil and acetone extract: Part 52. Journal of Food Science. 70, 208-215 (2005).

5. Zheng, G., Kenney, P. M. \& Lam, L. K. T. Anethofuran, carvone and limonene: potential cancer chemopreventive agents from dill weed oil and caraway oil. Planta Med. 58, 339-341 (1992).

6. Nautiyal, O. P. \& Tiwari, K. K. Extraction of dill seed oil (Anethum sowa) using supercritical carbon dioxide and comparison with hydrodistillation. Ind. Eng. Chem. Res. 50, 5723-5726 (2011).

7. Leopold, J., Gerhard, B., Albena, S. S., Evgenii, V. G. \& Stanka, T. D. Composition, quality control, and antimicrobial activity of the essential oil of long-time stored dill (Anethum graveolens L.) seeds from Bulgaria. J. Agric. Food Chem. 51, 38543857 (2003).

8. Zhi, Z., Chunyan, M., Xuening, Y. \& Zhuo, Z. Analysis of volatile components of Adenosma indianum (Lour.) Merr. by steam distillation and headspace solid-phase microextraction. Journal of Chemistry. 1-7 (3013).

9. Bakkali, F., Averbeck, S., Averbeck, D. \& Idaomar, M. Biological effects of essential oils - A review. Food and Chemical Toxicology. 46, 446-475 (2008).

10. Sikkema, J., De Bont, J. A. M. \& Poolman, B. Interactions of cyclic hydrocarbons with biological membranes. Journal of Biological Chemistry. 269, 8022-8028 (1994).

11. Delaquis, P. J., Stanich, K., Girard, B. \& Mazza, G. 2002. Antimicrobial activity of individual and mixed fractions of dill, cilantro, coriander and eucalyptus essential oils. International Journal of Food Microbiology. 74, 101-109 (2002).

12. Singh, G., Kapoor, I. P., Pandey, S. K. \& Singh, U. K. Singh, R. K. Studies on essential oils: antibacterial activity of volatile oils of some species. Phytother Res. 16, 680-682 (2002). 
13. Kaivan, K., Mahdi, A. \& Ilaria, P. Antifungal activity of the dill (Anethum graveolens L.) seed essential oil against strawberry anthracnose under in vitro and in vivo conditions. Archives of Phytopathology and Plant Protection. 49, 554-566(2016).

14. Yuxin, C. et al. Antifungal mechanism of essential oil from Anethum graveolens seeds against Candida albicans. Journal of Medical Microbiology. 62, 1175-1183 (2013).

15. Jun, T. et al. The mechanism of antifungal action of essential oil from dill (Anethum graveolens L.) on Aspergillus flavus.Plos One. (2012).

16. European Pharmacopoeia. Council of Europe 5th ed. Strasbourg. Vol. 2, 2710-2711 (2005).

17. Kurt, G. Making and manipulating capillary columns for gas chromatography, Dr. Alfred Huethig Verlag, Heidelberg. ISBN 3-7785-1312-5(1986).

18. The NIST 08 mass spectrometer database,Scientific Instrument Services Inc., New Jersey, http://www.sisweb.com/software/ms/nist.htm.

19. Wiley Registry ${ }^{\text {TM }}$ of Mass spectral data, 8th Edition, Scientific Instrument Services Inc., New Jersey, http://www.sisweb.com/software/ms/wiley.htm.

20. Robert, P. A. Identification of essential oil components by gas chromatography/mass spectrometry 4th Edn (Allured Publishing Corp, Carol Stream, Illinois, USA, 2007).

21. König, W. A., Joulain, D. \& Hochmuth, D. H. GC/MS Library: Terpenoids and related constituents of essential oils. (http://www.massfinder.com)

22. Van, D. D. H. \& Kratz, P. D. A generalization of the retention index system including linear temperature programmed gasliquid partition chromatography. J. Chromatography. 11, 463-471 (1963).

23. Gas Chromatographic Retention Data, http://webbook.nist.gov/chemistry/gc-ri/

24. Gong, L. \& Guo, S. Endophytic fungi from Dracaena cambodiana and Aquilaria sinensis and their antimicrobial activity. Afr. J. Biotechnol. 8, 731 (2009).

\section{Tables}

\section{Table 1}

Composition of the flowers, seeds, leaves \& stems of AG essential oils extracted using HS-SPME \& HD methods. 


\begin{tabular}{|c|c|c|c|c|c|c|c|c|c|c|}
\hline \multirow[t]{2}{*}{ No. } & \multirow[t]{2}{*}{ Compounds } & \multirow[t]{2}{*}{ Ret.time } & \multicolumn{2}{|c|}{ Flowers \% } & \multicolumn{2}{|c|}{ Seeds \% } & \multicolumn{2}{|c|}{ Leaves \% } & \multicolumn{2}{|c|}{ Stems \% } \\
\hline & & & HS-SPME & HD & HS-SPME & HD & HS-SPME & $\mathrm{HD}$ & HS-SPME & HD \\
\hline 1 & $\alpha$-Thujene & 14.66 & $\operatorname{tr}$ & 0.3 & $\operatorname{tr}$ & - & 0.2 & 0.4 & 0.1 & 0.4 \\
\hline 2 & 5-Methyl-3-heptanone & 15.03 & - & - & $\operatorname{tr}$ & - & - & - & 0.3 & - \\
\hline 3 & $\alpha$-Pinene & 15.11 & 0.2 & 1.4 & $\operatorname{tr}$ & $\operatorname{tr}$ & 0.4 & 2.5 & 0.2 & 2.4 \\
\hline 4 & Camphene & 15.89 & 0.1 & $\operatorname{tr}$ & $\operatorname{tr}$ & - & 0.1 & $\operatorname{tr}$ & $\operatorname{tr}$ & 0.1 \\
\hline 5 & Benzaldehyde & 16.16 & $\operatorname{tr}$ & - & - & - & 0.1 & - & - & - \\
\hline 6 & Sabinene & 16.96 & $\operatorname{tr}$ & 0.1 & $\operatorname{tr}$ & $\operatorname{tr}$ & 0.1 & 0.2 & $\operatorname{tr}$ & 0.2 \\
\hline 7 & $\beta$-Pinene & 17.26 & $\operatorname{tr}$ & 0.1 & $\operatorname{tr}$ & $\operatorname{tr}$ & 0.1 & 0.2 & $\operatorname{tr}$ & 0.1 \\
\hline 8 & Myrcene & 17.54 & 0.1 & 0.5 & 0.1 & 0.1 & 0.3 & 0.8 & 0.2 & 1.0 \\
\hline 9 & Dehydro-1,8-cineole & 17.75 & - & $\operatorname{tr}$ & - & - & - & 0.1 & - & 0.1 \\
\hline 10 & $\alpha$-Phellandrene & 18.48 & 2.9 & 34.6 & - & 0.5 & 6.1 & 61.4 & 1.1 & 58.9 \\
\hline 11 & Verbenene & 18.5 & - & - & 0.4 & - & - & - & - & - \\
\hline 12 & $\alpha$-Terpinene & 19.07 & 0.1 & $\operatorname{tr}$ & - & - & 0.2 & 0.1 & 0.1 & 0.1 \\
\hline 13 & 3-Carene & 19.12 & - & - & $\operatorname{tr}$ & - & - & - & - & - \\
\hline 14 & $p$-Cymene & 19.41 & 0.6 & 1.5 & 0.1 & 0.1 & 1.2 & 2.9 & 0.6 & 5.7 \\
\hline 15 & Limonene & 19.70 & 3.0 & 14.7 & 30.8 & 25.4 & 4.9 & 4.7 & 6.3 & 4.5 \\
\hline 16 & $\beta$-Phellandrene & 19.78 & 0.7 & 4.2 & - & - & 1.4 & 8.0 & - & 8.4 \\
\hline 17 & $\beta$-Ocimene & 20.38 & - & $\operatorname{tr}$ & - & - & $\operatorname{tr}$ & $\operatorname{tr}$ & - & $\operatorname{tr}$ \\
\hline 18 & Artemisia ketone & 20.96 & 0.1 & - & $\operatorname{tr}$ & - & 0.2 & - & 0.4 & - \\
\hline 19 & $\gamma$-Terpinene & 21.17 & $\operatorname{tr}$ & $\operatorname{tr}$ & $\operatorname{tr}$ & $\operatorname{tr}$ & 0.3 & 0.1 & 0.1 & 0.1 \\
\hline 20 & Octanol & 21.3 & $\operatorname{tr}$ & - & - & - & $\operatorname{tr}$ & - & - & - \\
\hline 21 & cis-Sabinene hydrate & 21.57 & 0.1 & - & - & - & 0.5 & - & $\operatorname{tr}$ & - \\
\hline 22 & 2-Nonanone & 22.41 & 0.3 & - & $\operatorname{tr}$ & - & 0.8 & - & 1.9 & - \\
\hline 23 & $p$-Cymenene & 22.66 & - & - & 0.2 & 0.2 & - & - & 0.2 & - \\
\hline 24 & Terpinolene & 22.65 & 0.1 & 0.1 & - & - & 0.2 & 0.2 & - & 0.2 \\
\hline 25 & Linalool & 22.92 & 0.1 & - & - & - & 1.0 & - & 0.3 & - \\
\hline 26 & Undecane & 22.96 & - & $\operatorname{tr}$ & $\operatorname{tr}$ & $\operatorname{tr}$ & - & 0.1 & - & $\operatorname{tr}$ \\
\hline 27 & Nonanal & 23.07 & $\operatorname{tr}$ & - & - & - & $\operatorname{tr}$ & - & 0.2 & - \\
\hline 28 & Phenyl ethyl alcohol & 23.77 & - & - & - & - & 0.1 & - & - & - \\
\hline 29 & cis-p-Menth-2-en-1-ol & 24.33 & - & $\operatorname{tr}$ & - & - & - & 0.1 & - & 0.1 \\
\hline 30 & cis-Limonene oxide & 24.9 & $\operatorname{tr}$ & - & 0.1 & 0.1 & - & - & - & - \\
\hline 31 & trans-Limonene oxide & 25.08 & $\operatorname{tr}$ & - & $\operatorname{tr}$ & 0.1 & - & - & - & - \\
\hline 32 & trans-p-Menth-2-en-1-ol & 25.17 & - & $\operatorname{tr}$ & - & - & - & 0.1 & - & 0.1 \\
\hline 33 & Camphor & 25.61 & 0.5 & $\operatorname{tr}$ & $\operatorname{tr}$ & - & 3.7 & $\operatorname{tr}$ & 0.6 & $\operatorname{tr}$ \\
\hline 34 & Menthone & 25.93 & - & $\operatorname{tr}$ & - & - & - & $\operatorname{tr}$ & - & - \\
\hline 35 & isomenthone & 26.44 & - & $\operatorname{tr}$ & - & - & - & $\operatorname{tr}$ & - & - \\
\hline 36 & Borneol & 26.68 & $\operatorname{tr}$ & - & - & - & 0.1 & $\operatorname{tr}$ & 0.1 & - \\
\hline 37 & Terpinen-4-ol & 27.22 & $\operatorname{tr}$ & $\operatorname{tr}$ & - & - & 0.1 & $\operatorname{tr}$ & - & 0.1 \\
\hline 38 & $p$-cymen-8-ol & 27.31 & - & $\operatorname{tr}$ & - & - & - & - & - & $\operatorname{tr}$ \\
\hline 39 & Dill ether & 27.58 & 8.5 & 5.7 & 0.1 & 0.1 & 7.3 & 9.2 & 4.1 & 10.3 \\
\hline 40 & $\alpha$-Terpineol & 27.77 & - & - & $\operatorname{tr}$ & - & $\operatorname{tr}$ & - & $\operatorname{tr}$ & - \\
\hline 41 & Estragol & 27.97 & - & - & - & - & - & 0.1 & - & 0.1 \\
\hline 42 & cis-Dihydrocarvone & 28.02 & 3.1 & 0.8 & 3.0 & 4.5 & 2.7 & - & 5.3 & - \\
\hline 43 & trans-Dihydrocarvone & 28.40 & 1.4 & 1.4 & 12.2 & 15.4 & 0.7 & - & 1.5 & - \\
\hline 44 & Dihydrocarveol isomer I & 28.82 & - & - & - & 0.2 & - & - & - & - \\
\hline 45 & iso-Dihydrocarveol & 28.84 & 0.2 & - & - & - & - & - & 0.3 & - \\
\hline 46 & Dihydrocarveol & 28.87 & $\operatorname{tr}$ & 0.1 & 0.1 & - & 0.1 & - & 0.1 & - \\
\hline 47 & Cumin aldehyde & 28.95 & - & - & - & - & 0.2 & 0.1 & 0.1 & $\operatorname{tr}$ \\
\hline 48 & Carveol & 29.03 & - & - & 0.1 & 0.2 & - & - & - & $\operatorname{tr}$ \\
\hline 49 & Dihydrocarveol isomer II & 29.49 & - & - & - & 0.5 & - & - & - & - \\
\hline 50 & neoiso-Dihydrocarveol & 29.52 & 0.4 & - & 0.2 & - & 0.1 & - & 0.5 & - \\
\hline 51 & Fenchyl acetate & 29.87 & - & - & - & - & 0.2 & 0.1 & - & 0.1 \\
\hline 52 & Pulegone & 30.07 & - & 0.2 & - & - & - & - & - & - \\
\hline 53 & Carvone & 30.35 & 22.6 & 11.3 & 17.7 & 30.8 & 14.1 & 0.4 & 14.3 & - \\
\hline 54 & Carvotanacetone & 30.48 & 0.1 & 0.1 & - & - & 0.2 & 0.1 & - & $\operatorname{tr}$ \\
\hline 55 & Piperitone & 30.78 & $\operatorname{tr}$ & - & - & - & $\operatorname{tr}$ & - & - & - \\
\hline 56 & Isopiperitenone & 31.55 & - & - & 0.1 & 0.1 & - & - & - & - \\
\hline 57 & Carvone oxide & 31.75 & $\operatorname{tr}$ & - & $\operatorname{tr}$ & $\operatorname{tr}$ & - & - & - & - \\
\hline 58 & E-Anethol & 32.12 & 0.2 & 0.1 & $\operatorname{tr}$ & 0.1 & 2.1 & 2.3 & - & 3.3 \\
\hline 59 & 2-Undecanone & 32.18 & - & - & - & - & - & - & 0.5 & - \\
\hline
\end{tabular}




\begin{tabular}{|c|c|c|c|c|c|c|c|c|c|c|}
\hline 60 & Bornyl acetate & 32.26 & 0.1 & - & - & - & 1.0 & - & 0.1 & - \\
\hline 61 & Carvacrol & 32.63 & 0.1 & 0.1 & $\operatorname{tr}$ & - & 0.6 & 0.1 & 0.7 & 0.1 \\
\hline 62 & Sabinyl acetate & 34.13 & $\operatorname{tr}$ & - & - & - & - & - & - & - \\
\hline 63 & Terpinyl acetate & 35.02 & - & - & $\operatorname{tr}$ & - & - & 0.1 & 0.1 & 0.1 \\
\hline 64 & Z-Ethyl cinnamate & 36.07 & 0.1 & - & - & - & 0.4 & - & $\operatorname{tr}$ & - \\
\hline 65 & E-Methyl cinnamate & 36.51 & 0.1 & - & - & - & 0.2 & - & - & - \\
\hline 66 & $\alpha$-Ylangene & 36.71 & - & - & - & - & - & 0.1 & - & - \\
\hline 69 & $E$ - $\beta$-Caryophyllene & 38.78 & 0.1 & - & - & - & 0.9 & - & 0.3 & - \\
\hline 70 & E- $\beta$-Farnesene & 39.56 & $\operatorname{tr}$ & - & - & - & 0.3 & - & 0.1 & - \\
\hline 71 & Dimethyltetrahydrobenzofuranone & 39.85 & 0.1 & - & - & - & 1.0 & - & - & - \\
\hline 72 & E-Ethyl cinnamate & 39.99 & 0.2 & - & - & - & 1.2 & - & 0.1 & - \\
\hline 73 & $\alpha$-Humulene & 40.23 & - & - & - & - & 0.1 & - & - & - \\
\hline 78 & Dihydroactinidiolide & 42.68 & - & - & - & - & 0.1 & - & - & - \\
\hline 79 & 6-Cadinene & 42.8 & - & - & - & - & 0.2 & - & - & - \\
\hline 80 & Elemicin & 43.37 & $\operatorname{tr}$ & 0.1 & 0.2 & 0.1 & 0.3 & $\operatorname{tr}$ & 0.1 & $\operatorname{tr}$ \\
\hline 81 & E-Nerolidol & 43.97 & 0.1 & - & - & - & 0.7 & - & 0.4 & - \\
\hline 82 & cis-Davanone & 44.98 & - & - & - & - & 0.9 & - & - & - \\
\hline 83 & Spathulenol & 45.25 & - & - & - & - & 0.1 & - & - & - \\
\hline 84 & Caryophyllene oxide & 45.57 & - & - & - & - & 0.1 & - & - & - \\
\hline 85 & Dill apiole & 46.77 & 46.9 & 20.0 & 33.3 & 20.9 & 16.0 & 2.6 & 31.9 & 1.5 \\
\hline 86 & Butylphthalide & 47.82 & 0.1 & - & - & - & 0.1 & - & - & - \\
\hline 87 & Apiol & 48.64 & 0.1 & - & $\operatorname{tr}$ & - & - & - & - & - \\
\hline \multicolumn{3}{|c|}{ Monoterpene hydrocarbons } & 12.3 & 59.7 & 46.8 & 46.2 & 18.9 & 81.5 & 15.7 & 82.1 \\
\hline \multicolumn{3}{|c|}{ Oxygenated Monoterpenes } & 24.2 & 11.8 & 18.3 & 32.0 & 22.0 & 1.0 & 17.1 & 0.5 \\
\hline \multicolumn{3}{|c|}{ Sesquiterpene hydrocarbone } & 0.7 & 0.1 & 0 & 0 & 8.4 & 0.4 & 2.5 & 0 \\
\hline \multicolumn{3}{|c|}{ Oxygenated Sesquiterpene } & 0.1 & 0 & 0 & 0 & 1.8 & 0 & 0.4 & 0 \\
\hline \multicolumn{3}{|c|}{ Fatty acid } & 0 & 0 & 0 & 0 & 0.1 & 0 & 0.6 & 0 \\
\hline \multicolumn{3}{|c|}{ Miscellaneous } & 59.3 & 27.5 & 33.8 & 21.4 & 31.9 & 14.6 & 41.4 & 15.5 \\
\hline
\end{tabular}

$\mathrm{Rt}=$ Retention time (min.), RI = Retention indices, $\mathrm{tr}=$ trace $(<0.05 \%)$; $*$ The isolated compounds are listed following their order of elution from the HP-5 MS column.

\section{Table 2}

Antimicrobial of the AG essential oils of seeds, flowers, stems \& leaves.

Data represent the diameter inhibition (in $\mathrm{mm}$ ). Results are the mean of three repetitions \pm standard deviation (SD) of the inhibition zone. na $=$ not active.

A.: Aspergillus, B.: Bacillus; E.: Enterobacter, E.: Escherichia; C.: Candida, L.: Listeria, P.: Pseudomonas

\section{Figures}




\begin{tabular}{|c|c|c|c|c|c|c|c|c|}
\hline \multirow{2}{*}{ Microbial strains } & \multirow{2}{*}{$\begin{array}{c}\text { Dose } \\
(\mu l)\end{array}$} & \multicolumn{4}{|c|}{ Essential oil } & \multicolumn{3}{|c|}{ Control } \\
\hline & & Seeds & Flowers & Leaves & Stems & Gentamicin & Tetracycline & Itraconazole \\
\hline \multirow[t]{2}{*}{ S. aureus CP011526 } & 10 & $17.0 \pm 0.80$ & $\begin{array}{c}15.0 \pm \\
0.00\end{array}$ & $\begin{array}{c}12.0 \pm \\
1.40\end{array}$ & $8.0 \pm 0.60$ & \multirow[t]{2}{*}{$6.0 \pm 0.00$} & \multirow[t]{2}{*}{$15.3 \pm 0.60$} & \multirow[t]{2}{*}{ na } \\
\hline & 20 & $25.0 \pm 0.00$ & $\begin{array}{c}17.0 \pm \\
0.10 \\
\end{array}$ & $\begin{array}{c}15.0 \pm \\
1.10 \\
\end{array}$ & $\begin{array}{c}11.0 \pm \\
0.60\end{array}$ & & & \\
\hline \multirow[t]{2}{*}{$\begin{array}{ll}B . & \text { licheniformis } \\
K X 785171 & \end{array}$} & 10 & $15.0 \pm 1.30$ & $\begin{array}{c}12.0 \pm \\
0.80\end{array}$ & $\begin{array}{c}11.0 \pm \\
1.40\end{array}$ & $8.0 \pm 0.60$ & \multirow[t]{2}{*}{$12.0 \pm 1.00$} & \multirow[t]{2}{*}{$18.2 \pm 1.80$} & \multirow[t]{2}{*}{ na } \\
\hline & 20 & $22.0 \pm 1.60$ & $\begin{array}{c}18.0 \pm \\
1.90\end{array}$ & $\begin{array}{c}12.0 \pm \\
1.50\end{array}$ & $\begin{array}{c}10.0 \pm \\
1.30\end{array}$ & & & \\
\hline \multirow[t]{2}{*}{ L. innocua DSM 20649} & 10 & $11.0 \pm 1.30$ & $9.0 \pm 1.20$ & $\begin{array}{l}7.0 \pm \\
0.90 \\
\end{array}$ & $7.0 \pm 0.10$ & \multirow[t]{2}{*}{$26.3 \pm 0.40$} & \multirow[t]{2}{*}{$21.2 \pm 1.80$} & \multirow[t]{2}{*}{ na } \\
\hline & 20 & $25.0 \pm 0.96$ & $\begin{array}{c}23.0 \pm \\
1.70\end{array}$ & $\begin{array}{l}19.0 \pm \\
2.30\end{array}$ & $\begin{array}{c}15.0 \pm \\
1.30\end{array}$ & & & \\
\hline \multirow[t]{2}{*}{$\begin{array}{l}E . \\
\text { xiangfangensis CP017183 }\end{array}$} & 10 & $11.0 \pm 0.31$ & $9.0 \pm 0.06$ & $\begin{array}{c}8.0 \pm \\
11.0\end{array}$ & $5.0 \pm 0.29$ & \multirow[t]{2}{*}{$8.0 \pm 0.00$} & \multirow[t]{2}{*}{$15.0 \pm 0.60$} & \multirow[t]{2}{*}{ na } \\
\hline & 20 & $13.0 \pm 0.82$ & $\begin{array}{c}12.0 \pm \\
0.12 \\
\end{array}$ & $\begin{array}{c}10.0 \pm \\
0.08\end{array}$ & $7.0 \pm 0.23$ & & & \\
\hline \multirow[t]{2}{*}{ E. fergusonii CU928158 } & 10 & $6.0 \pm 1.50$ & $6.0 \pm 0.00$ & $\begin{array}{l}4.0 \pm \\
0.60\end{array}$ & $2.0 \pm 1.70$ & \multirow[t]{2}{*}{$7.0 \pm 8.00$} & \multirow[t]{2}{*}{$10.0 \pm 1.0$} & \multirow[t]{2}{*}{ na } \\
\hline & 20 & $8.0 \pm 1.20$ & $7.0 \pm 1.00$ & $\begin{array}{l}5.0 \pm \\
0.90\end{array}$ & $3.0 \pm 1.00$ & & & \\
\hline \multirow[t]{2}{*}{$P$. aeruginosa NR117678 } & 10 & $4.0 \pm 1.50$ & $2.0 \pm 1.60$ & $\begin{array}{c}3.0 \pm \\
1.70 \\
\end{array}$ & $3.0 \pm 0.40$ & \multirow[t]{2}{*}{$11.0 \pm 0.60$} & \multirow[t]{2}{*}{$15.0 \pm 1.20$} & \multirow[t]{2}{*}{ na } \\
\hline & 20 & $8.0 \pm 1.80$ & $5.0 \pm 2.30$ & $\begin{array}{c}4.0 \pm \\
1.20 \\
\end{array}$ & $3.0 \pm 1.50$ & & & \\
\hline \multirow[t]{2}{*}{ C. albicans MF942350 } & 10 & $16.0 \pm 0.59$ & $\begin{array}{c}13.0 \pm \\
0.78\end{array}$ & $\begin{array}{c}11.0 \pm \\
1.38\end{array}$ & $7.0 \pm 1.52$ & \multirow[t]{2}{*}{ na } & \multirow[t]{2}{*}{ na } & \multirow[t]{2}{*}{$15.0 \pm 1.70$} \\
\hline & 20 & $18.0 \pm 0.80$ & $\begin{array}{c}16.0 \pm \\
0.90\end{array}$ & $\begin{array}{c}13.0 \pm \\
0.88\end{array}$ & $\begin{array}{c}10.0 \pm \\
1.08 \\
\end{array}$ & & & \\
\hline \multirow[t]{2}{*}{ C. parapsilosis MF942354 } & 10 & $18.0 \pm 2.30$ & $\begin{array}{c}12.0 \pm \\
1.10 \\
\end{array}$ & $\begin{array}{l}9.0 \pm \\
1.00 \\
\end{array}$ & $9.0 \pm 0.84$ & \multirow[t]{2}{*}{ na } & \multirow[t]{2}{*}{ na } & $17.0 \pm 2.00$ \\
\hline & 20 & $20.0 \pm 1.90$ & $\begin{array}{c}15.0 \pm \\
0.72\end{array}$ & $\begin{array}{c}11.0 \pm \\
1.80\end{array}$ & $\begin{array}{c}10.0 \pm \\
0.78\end{array}$ & & & \\
\hline $\begin{array}{l}\text { A. parasiticus } \quad \text { CBS } \\
100926\end{array}$ & 10 & $25.0 \pm 0.14$ & $\begin{array}{c}21.0 \pm \\
0.80\end{array}$ & $\begin{array}{c}19.0 \pm \\
0.70\end{array}$ & $\begin{array}{c}11.0 \pm \\
0.14\end{array}$ & na & na & $19.0 \pm 1.60$ \\
\hline & 20 & $42.0 \pm 0.30$ & $\begin{array}{l}33.0 \pm \\
0.54\end{array}$ & $\begin{array}{l}25.0 \pm \\
0.23\end{array}$ & $\begin{array}{l}22.0 \pm \\
1.50\end{array}$ & & & \\
\hline
\end{tabular}




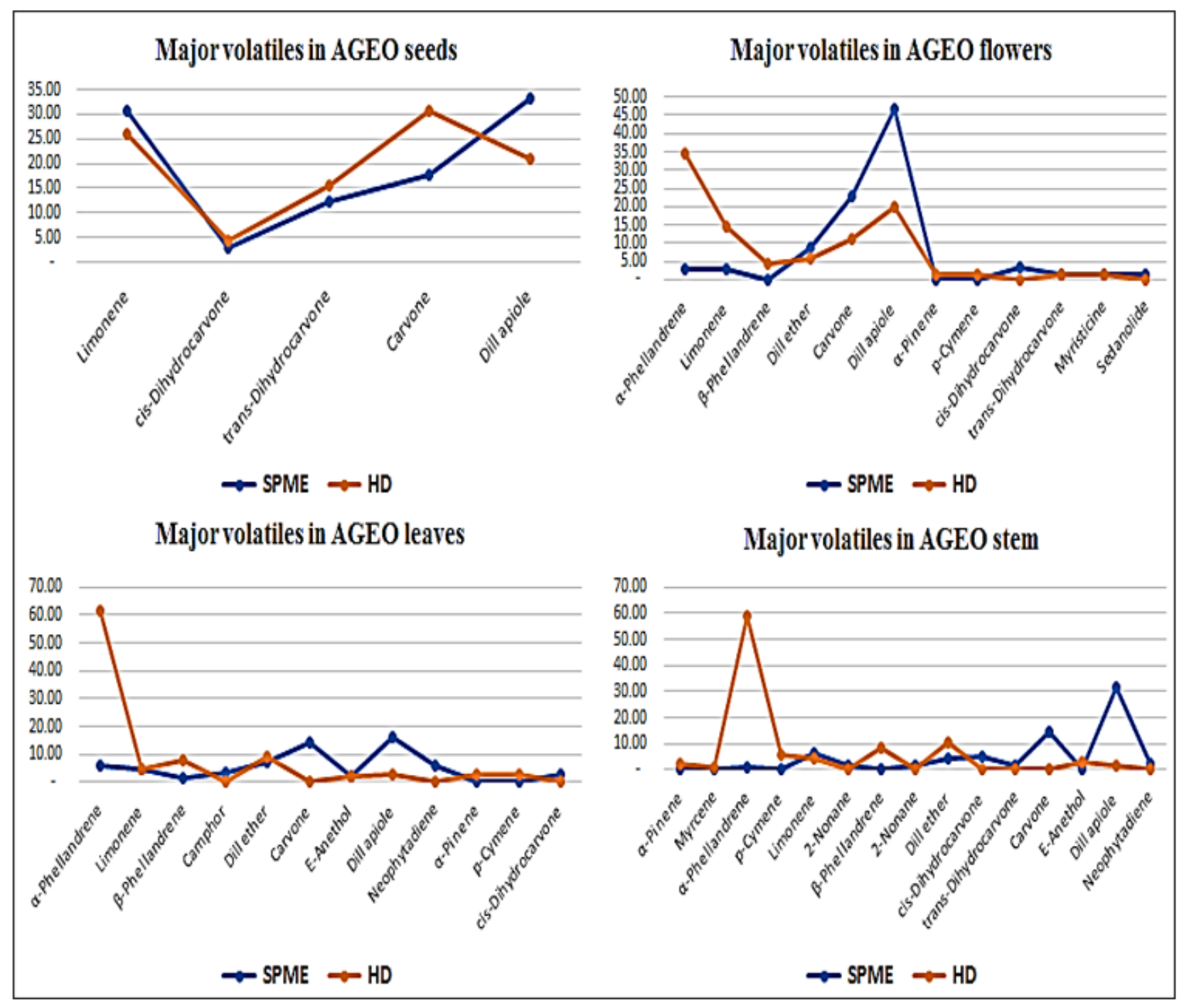

Figure 1

Peak areas of major volatiles in seeds, flowers, leaves \& stems of A. graveolens 


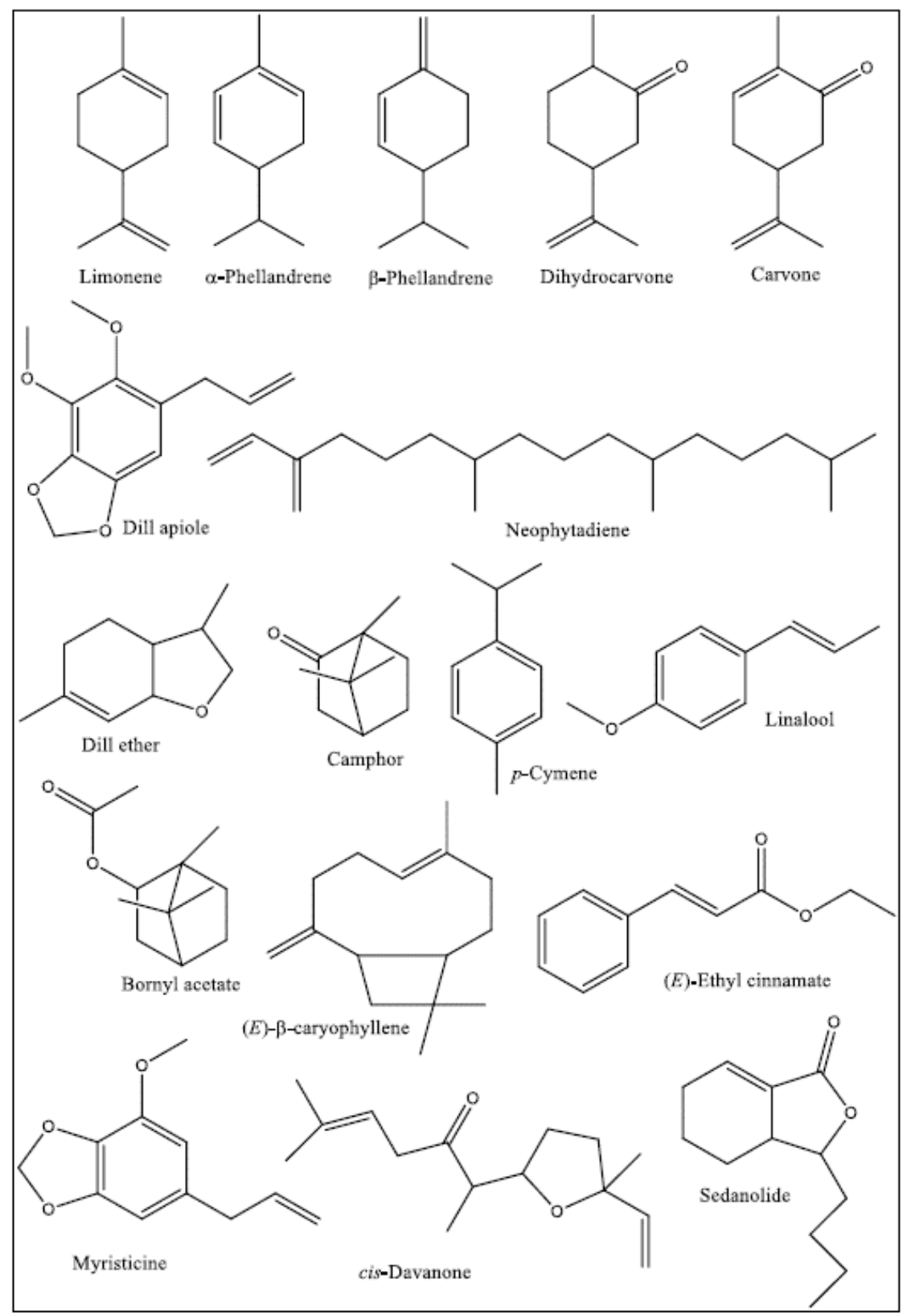

Figure 2

Structures of major constituents in essential oils of AG seeds, flower, leaves, and stems

\section{Supplementary Files}

This is a list of supplementary files associated with this preprint. Click to download.

- Supplementarymaterial.doc 